\title{
DEVELOPMENT OF A TECHNIQUE TO DETERMINE THE 3D ELASTICITY TENSOR OF WOOD AS APPLIED TO DRYING STRESS MODELING
}

\author{
Aziz Laghdir ${ }^{1}$, Yves Fortin ${ }^{1}$, Carmen Mariella De la Cruz ${ }^{2}$ and Roger E. Hernández ${ }^{1}$
}

\begin{abstract}
The objective of this study was to develop an accurate and simple method for measuring the engineering coefficients of the 3D elasticity tensor of wood. A method using a semi-ring extensometer (SRE) and a compression specimen (6-specimen technique) is proposed. The SRE is made of a semi-ring stainless steel blade pin-jointed to two aluminum fixing plates, and two resistance strain gauges bonded to the top and bottom faces of the blade at mid-span position. Groups of five matched compression specimens (20 mm x $20 \mathrm{~mm}$ x $60 \mathrm{~mm}$ ) from black spruce wood (Picea mariana (Mill.) B.S.P.), cut in six different orientations with respect to load axis (three orthotropic directions and three diagonal directions at an angle of 45 degrees to the load axis) were used for the calibration of the SRE. A resistance strain gauge bonded directly to the wood surface was used as a reference for both the axial and transverse measurements. The validation of the technique was made with another series of specimens cut in the same six orientations. The axial strain data of the SRE were then compared to the ones obtained from a linear displacement sensor (LVDT). For the transverse directions, the SRE results in terms of Poisson's ratios and shear moduli were compared with corresponding data obtained from the literature. Results showed that the $\mathrm{R}^{2}$ value of the relationship between the Young's moduli determined with the SRE and the LVDT varied from 0.88 to 0.97 . The SRE technique appeared also reliable to evaluate both the Poisson's ratios and shear moduli as the obtained values were in good agreement with the literature data. As compared to bonded strain gauges, the SRE technique is reusable, simpler and cheaper to use and its sensitivity is nearly independent of temperature.
\end{abstract}

Keywords: 3D elasticity tensor of wood, semi-ring extensometer, 6-specimen technique, axial and transverse strain measurements, wood drying.

\section{INTRODUCTION}

The present study is part of a larger project on the modeling of the mechanical behaviour of wood during kiln drying (Moutee et al. 2005, Moutee et al. 2007). The development of any mathematical model for the prediction of drying stresses in wood requires, among other mechanical properties, the evaluation of the elasticity tensor of wood under hygrothermal conditions pertaining to industrial kiln drying. All components of the elasticity tensor have to be accurately quantified for the evaluation of the actual 3D state of stress and strain during the course of drying. However, the experimental determination of the elastic tensor coefficients is not an easy task due to the natural variability, heterogeneity and anisotropy of wood. The task is even more challenging when it has to be conducted under the harsh conditions commonly occurring during lumber drying. 
Wood is an orthotropic material characterized by three mutually perpendicular planes of symmetry (Kollmann and Côté 1968). Thus, its elastic behaviour can be defined by nine independent elastic compliance coefficients $\left(\mathrm{S}_{11}, \mathrm{~S}_{22}, \mathrm{~S}_{33}, \mathrm{~S}_{12}, \mathrm{~S}_{13}, \mathrm{~S}_{23}, \mathrm{~S}_{44}, \mathrm{~S}_{55}\right.$ and $\mathrm{S}_{66}$; where the subscripts 1,2 and 3 indicate the radial (R), tangential (T) and longitudinal (L) directions, respectively; and the subscripts 44, 55 and 66, indicate the LR, LT and RT shear-planes, respectively). The elastic behaviour can also be represented by twelve engineering elastic parameters (three Young's moduli: $\mathrm{E}_{\mathrm{R}}, \mathrm{E}_{\mathrm{T}}, \mathrm{E}_{\mathrm{L}}$; six Poisson's ratios: $v_{\mathrm{LR}}, v_{\mathrm{LT}}, v_{\mathrm{RL}}, v_{\mathrm{RT}}, v_{\mathrm{TL}}, v_{\mathrm{TR}}$; and three shear moduli: $\mathrm{G}_{\mathrm{LR}}, \mathrm{G}_{\mathrm{LT}}, \mathrm{G}_{\mathrm{RT}}$ ). The matrix form of Hooke's law when the compliance coefficients are expressed in terms of the engineering parameters takes the form (Bodig and Jayne 1982):

$$
\left[\begin{array}{l}
\varepsilon_{\mathrm{R}} \\
\varepsilon_{\mathrm{T}} \\
\varepsilon_{\mathrm{L}} \\
\gamma_{\mathrm{LR}} \\
\gamma_{\mathrm{LT}} \\
\gamma_{\mathrm{RT}}
\end{array}\right]=\left[\begin{array}{cccccc}
1 / \mathrm{E}_{\mathrm{R}} & -v_{\mathrm{TR}} / \mathrm{E}_{\mathrm{T}} & -v_{\mathrm{LR}} / \mathrm{E}_{\mathrm{L}} & & & \\
-v_{\mathrm{RT}} / \mathrm{E}_{\mathrm{R}} & 1 / \mathrm{E}_{\mathrm{T}} & -v_{\mathrm{LT}} / \mathrm{E}_{\mathrm{L}} & 0 & \\
-v_{\mathrm{RL}} / \mathrm{E}_{\mathrm{R}} & -v_{\mathrm{TL}} / \mathrm{E}_{\mathrm{T}} & 1 / \mathrm{E}_{\mathrm{L}} & & & \\
& & & 1 / \mathrm{G}_{\mathrm{LR}} & & \\
& 0 & & & 1 / \mathrm{G}_{\mathrm{LT}} & \\
& & & & & 1 / \mathrm{G}_{\mathrm{RT}}
\end{array}\right]\left[\begin{array}{c}
\sigma_{\mathrm{R}} \\
\sigma_{\mathrm{T}} \\
\sigma_{\mathrm{L}} \\
\tau_{\mathrm{LR}} \\
\tau_{\mathrm{LT}} \\
\tau_{\mathrm{RT}}
\end{array}\right]
$$

where : $\varepsilon, \sigma:$ normal strain and stress

$\gamma, \tau$ : shear strain and stress.

From symmetry consideration of the compliance matrix, we obtain:

$$
v_{i j} / E_{i}=v_{j i} / E_{j} \quad \text { where } i \neq j
$$

The Young's modulus in the longitudinal direction $\left(\mathrm{E}_{\mathrm{L}}\right)$ is well documented for most commercial species. However, very few data are available for the other elastic parameters because of the difficulty in measuring strain properly, particularly in the directions perpendicular to applied load (transverse strain). Bonded resistance strain gauges are widely used to measure surface strain in various materials including wood (Sliker 1991, Sliker et al. 1994). However, these gauges are expensive and can only be used once.

The most detailed studies on elastic parameters have focussed on finding relationships between engineering elastic parameters, using the longitudinal Young's modulus and wood density as independent variables for predicting the other elastic parameters (Hearmon 1948, Bodig and Goodman 1973, Guitard 1987, Guitard and El Amri 1987, Sliker et al. 1994, Laghdir 2000). However, this approach requires a large range of wood density values and the predictions remain often approximate. Nondestructive measurement techniques were also used for the determination of elastic properties of wood. Among these, the ultrasonic technique seems the most reliable. The apparent moduli obtained from the ultrasonic technique are greater than the static moduli, although the dynamic and static moduli are generally strongly correlated (Bucur 1995, Yang and Fortin 2001, Dieter et al. 2007).

The objective of this research was to develop an accurate and simple method for measuring the 3D elasticity tensor of wood using a semi-ring extensometer (SRE) and the so-called 6-specimen technique (Guitard 1987, Laghdir 2000). The paper focuses mainly on the calibration and validation of the SRE sensor developed for this application. 


\section{MATERIAL AND METHODS}

\section{Extensometer construction}

A schematic diagram of the semi-ring extensometer is shown in Figure 1a. This is an improved version of the SRE developed by Fortin et al. (1994) for the measurement of surface strain during drying. The SRE is composed of a $0.45 \mathrm{~mm}$-thick and $6.35 \mathrm{~mm}$-wide stainless steel blade bent with a 16.4-mm radius and two electrical strain gauges (type CEA-06-125AC-350) bonded at the top and bottom half-positions of the semi-ring. These two strain gauges are wired so as to achieve maximum output and temperature compensation (Fortin et al. 1994). The blade is pin-jointed to two aluminum fixing plates attached on the wood surface with wood screws. Two holes of $2 \mathrm{~mm}$ in diameter, $6 \mathrm{~mm}$ deep and $10 \mathrm{~mm}$ apart are bored in the wood specimen to fix the sensor (Figure 1b). A small aluminum disc is placed between the fixing plates and the specimen surface to minimize the friction during the plate displacement.
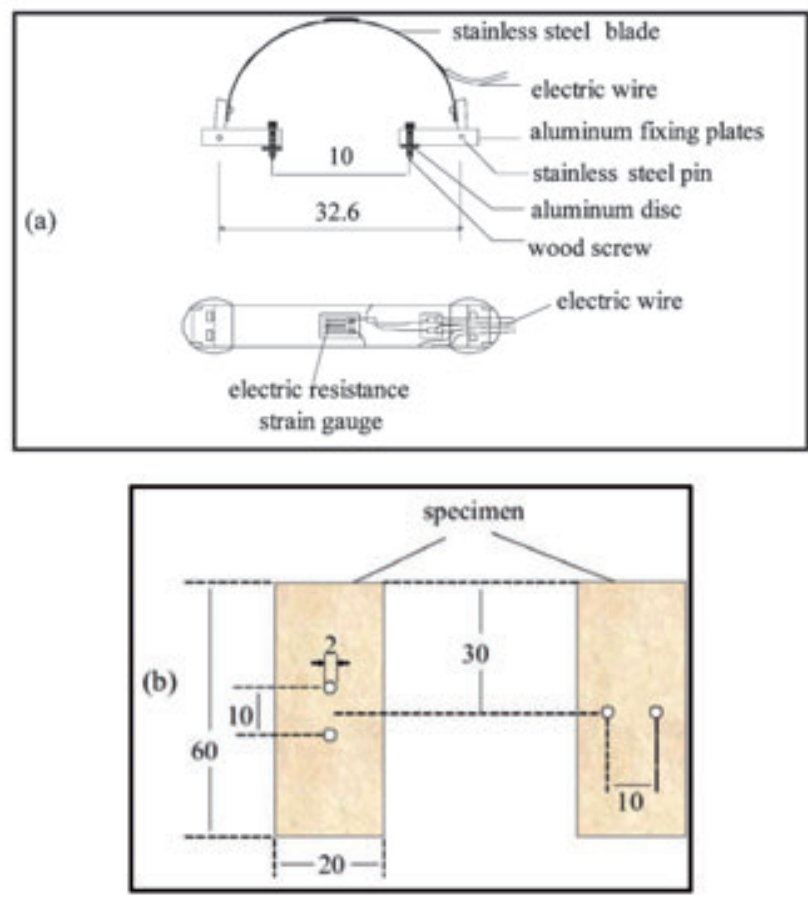

Fig 1: (a) Schematic diagram of the SRE; (b) Axial and transverse positions of the holes for the SRE fixation to the wood surface (distances are in $\mathrm{mm}$ ).

\section{Test specimens}

The test material was prepared according to the 6-specimen technique which consists of using six specimen orientations: three orthotropic directions and three diagonal directions at an angle of 45 degrees to the load axis. The specimen dimensions were $20 \mathrm{~mm} \times 20 \mathrm{~mm}$ in cross section and $60 \mathrm{~mm}$ along the loading direction. All specimens from a given group came from the outer wood zone, the same tree and the same bolt. The specimens were obtained from boards of 25 by $75 \mathrm{~mm}$ in cross section cut from green 2.44-m long bolts of black spruce (Picea mariana (Mill.) B.S.P.) coming from four trees. The boards were first slowly dried at $14 \%$ moisture content (MC) and then conditioned during several weeks at $21^{\circ} \mathrm{C}$ and $60 \%$ relative humidity $(\mathrm{RH})$ in order to obtain a final equilibrium moisture content (EMC) of about $12 \%$. Much care was taken to get the proper orientation of the boards and the specimens with respect to the orthotropic directions. A maximum 3-degree grain deviation was allowed for the longitudinally oriented specimens. Concerning ring curvature in the tangential direction, it was minimized by cutting the specimen as close as possible to the bark. 
Based on the working principle of the 6-specimen technique, the measurement of axial and transverse strains on the specimens oriented in the orthotropic directions should be carried out simultaneously. However, because of constraints imposed by the SRE attachment system on the test specimen, three other specimens oriented in the $\mathrm{L}, \mathrm{L}$ and $\mathrm{T}$ directions were added to each group for the transverse strain measurement in the $\mathrm{R}, \mathrm{T}$ and $\mathrm{R}$ directions, respectively. This led to nine specimens per group: three oriented in the orthotropic directions, R, T and L (Figure 2a), and three oriented in the diagonal directions, LR, LT and TR (Figure 2b) for the axial strain measurement, as well as three specimens oriented in L, $\mathrm{L}$ and $\mathrm{T}$ directions for the transverse strain measurement (Figure 2c).

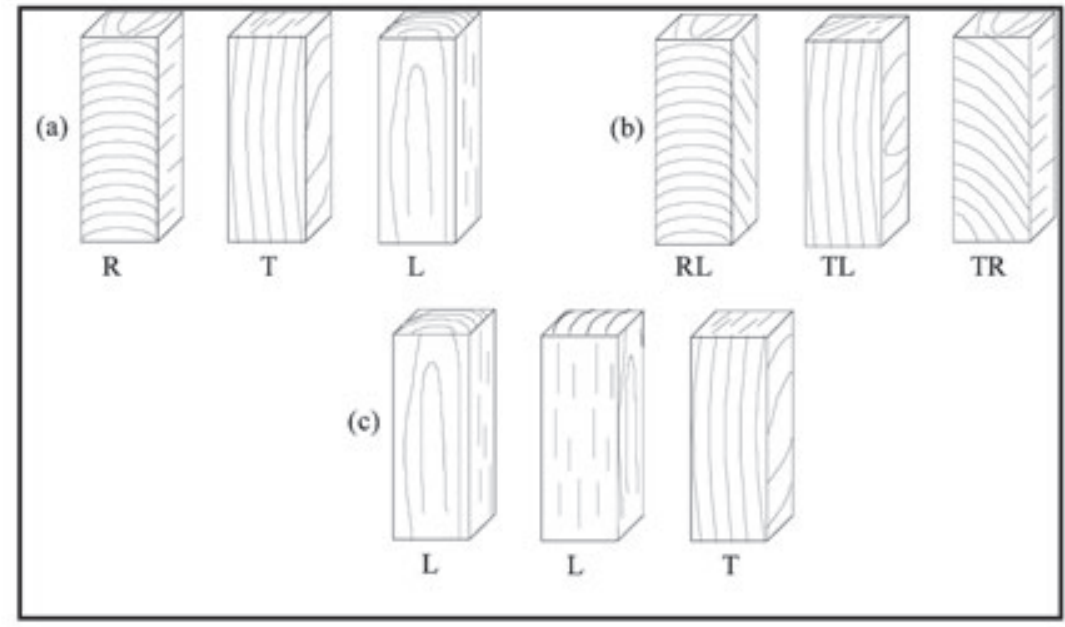

Fig 2: Group of nine matched specimens. (a) orthotropic directions; (b) diagonal directions; (c) specimens oriented in L, L, and T directions. (a) and (b) for the axial strain measurements and (c) for the transverse strain measurements.

Young's moduli $\mathrm{E}_{\mathrm{R}}, \mathrm{E}_{\mathrm{T}}$ and $\mathrm{E}_{\mathrm{L}}$ were obtained directly from samples R, T and L (Figure 2a). These moduli were combined to the transverse strain measurements made in samples $\mathrm{L}, \mathrm{L}$ and $\mathrm{T}$ (Figure $2 \mathrm{c}$ ) so as to obtain Poisson's ratios $v_{\mathrm{RL}}, v_{\mathrm{TL}}, v_{\mathrm{RT}}$. However, the values of $v_{\mathrm{LR}}, v_{\mathrm{LT}}$ and $v_{\mathrm{TR}}$ were deduced from the symmetry of the $2 \mathrm{D}$ elasticity tensor using Eq. (2). The shear moduli $\mathrm{G}_{\mathrm{LR}}, \mathrm{G}_{\mathrm{LT}}$ and $\mathrm{G}_{\mathrm{RT}}$ were obtained from the off-axes specimens RL, TL and RT (Figure 2b), respectively, using the following equations:

$$
\begin{aligned}
& \frac{1}{\mathrm{G}_{\mathrm{LR}}}=\frac{4}{\mathrm{E}_{\mathrm{LR}}}-\frac{1}{\mathrm{E}_{\mathrm{L}}}-\frac{1}{\mathrm{E}_{\mathrm{R}}}+\frac{2 v_{\mathrm{RL}}}{\mathrm{E}_{\mathrm{L}}} \\
& \frac{1}{\mathrm{G}_{\mathrm{LT}}}=\frac{4}{\mathrm{E}_{\mathrm{LT}}}-\frac{1}{\mathrm{E}_{\mathrm{L}}}-\frac{1}{\mathrm{E}_{\mathrm{T}}}+\frac{2 v_{\mathrm{TL}}}{\mathrm{E}_{\mathrm{L}}} \\
& \frac{1}{\mathrm{G}_{\mathrm{RT}}}=\frac{4}{\mathrm{E}_{\mathrm{RT}}}-\frac{1}{\mathrm{E}_{\mathrm{R}}}-\frac{1}{\mathrm{E}_{\mathrm{T}}}+\frac{2 v_{\mathrm{RT}}}{\mathrm{E}_{\mathrm{T}}}
\end{aligned}
$$

where $\mathrm{E}_{\mathrm{LR}}, \mathrm{E}_{\mathrm{LT}}$ and $\mathrm{E}_{\mathrm{RT}}$ are the apparent moduli obtained from the off-axes specimens.

Five groups (5 replicates) of nine matched specimens each were used for the SRE calibration. Ten other groups were used for the validation of the technique. The mean basic density of the specimens expressed as the ratio of oven-dry mass to green volume was $390 \mathrm{~kg} / \mathrm{m}^{3}$. The coefficient of variation (CV) within matched sample groups varied between $0.74 \%$ and $5.0 \%$. The average $\mathrm{CV}$ inter-group was about $9.5 \%$. Tangential specimens contributed for an important part of the density variation. 
The 6-specimen technique allows the measurement of all engineering elastic coefficients by using only an axial loading test in compression or in tension. The compression specimen was chosen mainly because its relatively small dimensions are suitable for sampling the tree in the three structural directions. Nevertheless, it requires a meticulous specimen preparation and a proper specimen matching technique. Sample set homogeneity is important so as to minimize the effect of within-tree variability of the elastic properties, especially with respect to the longitudinal and radial variability. This is done through proper specimen preparation procedure. The 6-specimen technique may not be the most appropriate if it were to be used to determine the difference in hygro-elastic properties between core and outer wood in small diameter trees. To our knowledge, there are not however too many alternative techniques to make this type of study, except perhaps for the ultrasonic technique (Bucur 1995), which then would be difficult to apply in the harsh hygrothermic conditions of wood drying. Furthermore, even if the effects of moisture content and temperature on the 3D elasticity tensor component values were determined for the outer wood only, this would be in itself a great asset for the simulation of drying stresses since such data are almost absent from the wood science literature.

\section{Extensometers calibration}

Two SREs (SRE-1 and SRE-2) were used in this study. A Sangamo DG 1.0 linear sensor (LVDT) was also used as a reference instrument for Young's moduli determination. A two-side clip gauge provided with the LVDT sensor allowed the strain measurement over a span of $40 \mathrm{~mm}$ in the central section of the specimen. The LVDT was calibrated using a Boeckler extensometer (Boeckler Instruments) having an accuracy of $\pm 0.0025 \mathrm{~mm}$.

The SRE calibration was made using a resistance strain gauge as a reference for both the axial and transverse strain measurements. In the later case, this calibration technique was found to be much more reliable than the straight displacement technique using the Boeckler extensometer. Depending on the type of strain measured, the SRE was fixed on one face of the specimen in the axial or transverse direction and the strain gauge (type CEA-06-125AC-350) was bonded on the opposite face in the same central position (Figure $1 \mathrm{~b}$ ). The compression tests were carried out with a Riehle testing machine equipped with an appropriate load cell and surrounded by a built-in environmental chamber maintained at $21^{\circ} \mathrm{C}$ and $60 \% \mathrm{RH}$. The readings of the load cell and the two strain sensors were recorded on a Sciemetrics Instruments Series 7000 data acquisition system allowing real-time visualization of the measured data and computer storage to one second interval.

\section{Validation of the SRE measurement technique}

In order to validate the SRE measurement technique for determining the engineering coefficients of the $3 \mathrm{D}$ elasticity tensor, axial strain measurements were made simultaneously using the LVDT and the two SREs (Figure 3a). Only the SREs were used for the transverse strain measurements (Figure 3b).

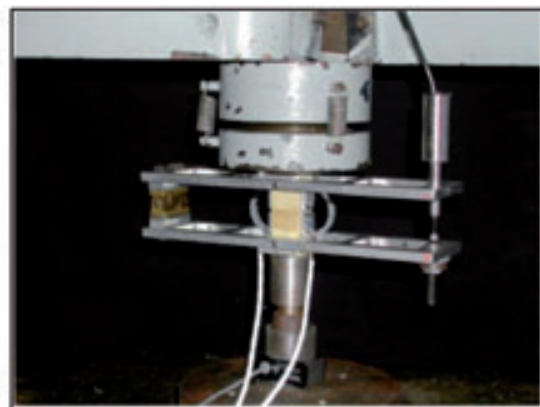

(a)

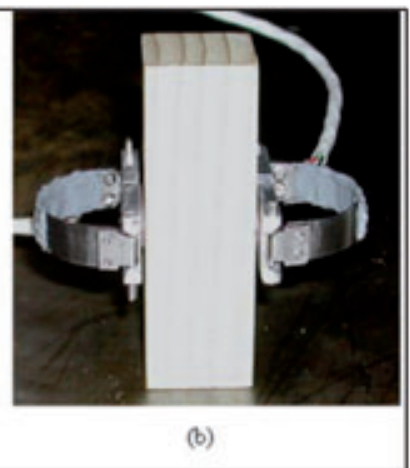

(b)

Fig 3: (a) LVDT and SRE setups for axial strain measurements; (b) SRE positions for transverse strain measurements during the validation tests. 


\section{RESULTS AND DISCUSSION}

\section{Calibration}

The two SREs were calibrated individually for determining the linear relationship between the surface strain obtained with the resistance strain gauge bonded on the specimen surface and the output voltage of the SRE. A calibration coefficient was then determined for each specimen orientation. As shown in Table 1, the values of the calibration coefficients are fairly similar for the two SREs although SRE-1 tends to give higher values for the axial strains. Furthermore, the mean value of the axial calibration coefficient varies little with specimen orientation, except in the $\mathrm{R}$ direction. However, the transverse calibration coefficient shows a large variation between the three specimen orientations, especially in the transverse plane (last row in Table 1). Standard error values for the calibration coefficients showed in Table 1 tend to be greater for the axial strain measurements than for the transverse strain measurements, with a maximum value of $2.59 \mu$ strain / $\mathrm{mV}$ for the tangentially oriented specimens.

Table 1: SRE calibration coefficient for each specimen orientation (standard error values within brackets).

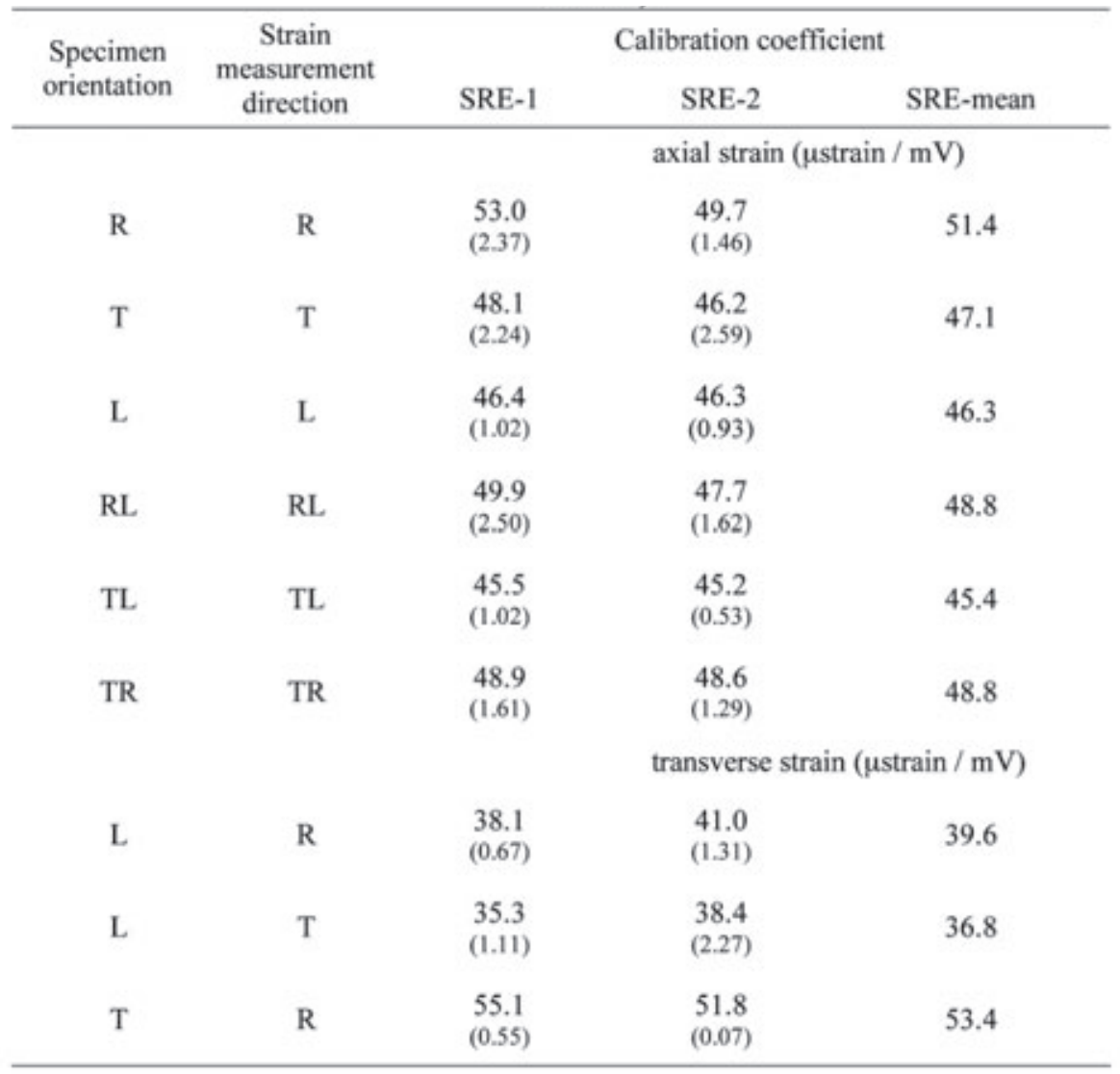

The variation in the calibration coefficients can be explained by the specific characteristics of each SRE and the variability of wood. It can also be related to the position of the retaining wood screws within the annual growth zone. The effect is particularly important when the retaining screws are fixed in the longitudinal direction (first and last rows of Table 1). Thus, only the mean calibration coefficient was considered for the determination of all elastic parameters in the validation tests. It is therefore important to use as many as possible specimen groups to determine a specific set of elastic coefficients. Ten replicates can be considered as a minimum in this regard. 


\section{Validation of the SRE measurement technique}

Young's moduli

The values of the Young's moduli obtained for the validation of the SRE measurement technique are presented in Figure 4. The $\mathrm{R}^{2}$ value of the relationship between the Young's moduli determined with the SRE and the LVDT varied from 0.88 to 0.97 . If LVDT results are taken as reference values, no significant difference is noted between the SRE and LVDT Young's moduli in the R and L directions. At first glance, the SRE seems to underestimate the Young's modulus in the T direction. This apparent discrepancy could be related to the effective strain span of each one of the techniques used, which was 10 $\mathrm{mm}$ for the SRE and $40 \mathrm{~mm}$ for the LVDT. Since the strains were measured on the RT face, the effective span of the SRE had more chances to be aligned with the growth rings than that of the LVDT. Therefore, a correction should rather be applied to the LVDT values obtained in the T direction, especially if the specimens come from log of small diameters.
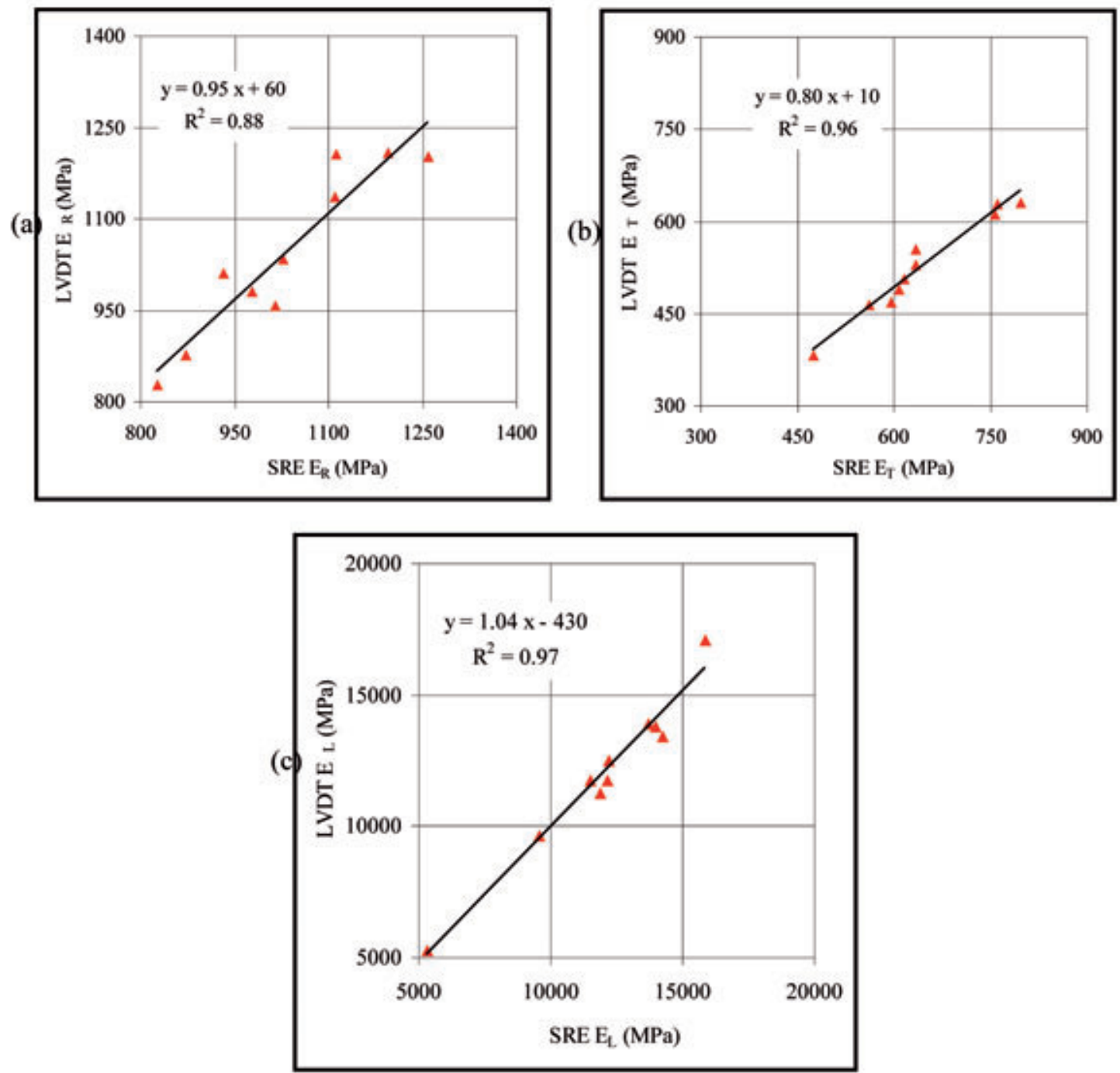

Fig. 4: Relationship between Young's moduli obtained in the three orthotropic directions with the SRE and LVDT sensors: (a) R-direction; (b) T-direction; (c) L-direction. 


\section{Poisson's ratios}

The values obtained for the Poisson's ratios are presented in Table 2. Note that only $v_{\mathrm{RL}}, v_{\mathrm{TL}}$ and $v_{\mathrm{RT}}$ were measured. As mentioned earlier, the values of $v_{\mathrm{LR}}, v_{\mathrm{LT}}$ and $v_{\mathrm{TR}}$ were deduced from the symmetry of the 3D elasticity tensor using Eq. (2).

The Poisson's ratio $v_{\mathrm{ij}}$ is defined as being the ratio of the transverse strain in the " $\mathrm{i}$ " direction to the axial strain resulting from the loading in the " $\mathrm{j}$ " direction. For an anisotropic material such as wood, this coefficient is also an indicator of anisotropy between two mutually perpendicular directions. As shown in Table 2, the $v_{\mathrm{RL}}$ and $v_{\mathrm{TL}}$ coefficients are much higher than the $v_{\mathrm{LR}}$ and $v_{\mathrm{LT}}$ coefficients. This is easily explained by the lower stiffness in the $\mathrm{R}$ and $\mathrm{T}$ directions as compared to that in the longitudinal direction. The very low values of the $v_{\mathrm{LR}}$ and $v_{\mathrm{LT}}$ coefficients make their experimental determination very difficult, the transverse strain being very small (less than $10 \mu$ strains in this study). This is why it becomes more convenient to deduce those Poisson's ratios from calculations.

Taking into account the standard deviation values, the results of the Poisson's ratios appear to be in good agreement with the literature data (Table 2). This indicates that the experimental technique used for the measurement of the 3D elasticity tensor of wood is reliable.

Table 2: Poisson's ratios obtained from the validation tests at 12\% EMC (standard deviation values within brackets), as compared to data from literature.

\begin{tabular}{cccccccc}
\hline & $\begin{array}{c}\text { Basic } \\
\text { density } \\
\left(\mathrm{kg} / \mathrm{m}^{3}\right)\end{array}$ & $v_{\mathrm{RL}}$ & $v_{\mathrm{TL}}$ & $v_{\mathrm{RT}}$ & $v_{\mathrm{LR}}$ & $v_{\mathrm{LT}}$ & $v_{\mathrm{TR}}$ \\
\hline Present study & 390 & $\begin{array}{c}0.33^{(1)} \\
(0.06)\end{array}$ & $\begin{array}{c}0.42^{(1)} \\
(0.07)\end{array}$ & $0.32^{(1)}$ & $0.029^{(2)}$ & $0.025^{(2)}$ & $0.51^{(2)}$ \\
\hline $\begin{array}{c}\text { Bodig and } \\
\text { Goodman (1973) } \\
\text { Softwoods }\end{array}$ & $-\cdots$ & 0.37 & 0.42 & 0.35 & 0.041 & 0.033 & 0.42 \\
\hline
\end{tabular}

(1): measured values; (2): inferred values.

\section{Shear moduli}

The results obtained for the shear moduli are shown in Table 3. Considering the differences in density and the standard deviation values of the experimental data, the measured shear moduli are also in good agreement with the literature data. It is also noted that the values obtained for the shear moduli follow the well-known relation of order, $\mathrm{G}_{\mathrm{RT}}<<\mathrm{G}_{\mathrm{LT}}<\mathrm{G}_{\mathrm{LR}}$. The LR plane which contains longitudinal tracheids reinforced by transverse rays is the most rigid, whereas the RT plane which contains only the ray cells as elements of reinforcement, is the least resistant to shearing. 
Table 3: Shear moduli obtained from the validation tests (standard deviation values within brackets), as compared to data from literature (at 12\% EMC).

\begin{tabular}{ccccc}
\hline & $\begin{array}{c}\text { Basic } \\
\text { density } \\
\left(\mathrm{kg} / \mathrm{m}^{3}\right)\end{array}$ & $\begin{array}{c}\mathrm{G}_{\mathrm{LR}} \\
(\mathrm{MPa})\end{array}$ & $\begin{array}{c}\mathrm{G}_{\mathrm{LT}} \\
(\mathrm{MPa})\end{array}$ & $\begin{array}{c}\mathrm{G}_{\mathrm{RT}} \\
(\mathrm{MPa})\end{array}$ \\
\hline Present study & 390 & 841 & 798 & 55 \\
\hline $\begin{array}{c}\text { Bodig and Goodman } \\
\text { (1973) } \\
\text { Black spruce }\end{array}$ & 380 & 699 & 663 & $(7)$ \\
\hline
\end{tabular}

\section{CONCLUSION}

The use of the SRE combined with the 6-specimen technique (compression specimen) to measure both axial and transverse strains appears to be a reliable method to determine the $3 \mathrm{D}$ elasticity tensor of wood. The SRE is particularly suitable for the transverse strain measurement. A different calibration coefficient has to be applied to the SRE measurement for each specimen orientation. The use of a large number of sample sets is suggested (a minimum of 10 sample sets) in order to compensate for the uncertainty in the calibration coefficient values and within-tree variability of wood properties. The within-sample set variability also needs to be controlled by using a proper specimen matching procedure. More research is needed in order to simulate the influence of the screw holes effect while taking both the axial and transverse strain measurement simultaneously on the same specimen. The effect of temperature has also to be investigated although in theory it should be very small. 


\section{REFERENCES}

Bodig, J.; Goodman, J. B. 1973. Prediction of elastic parameters for wood. Wood Sci. 5(4): 249-264.

Bodig, J.; Jayne, B. 1982. Mechanics of Wood and Wood Composites. Van Nostrand Reinhold Company, 15th edition, New York.

Bucur, V. 1995. Acoustics of Wood. CRC Press, New York.

Dieter, L.; Puchegger, S; Gierlinger, N.; Beikircher, W.; Stanzl-Tchegg, S. 2007. Elastic properties of thermally treated wood at elevated temperatures. Proceedings of Third International Symposium on Wood Machining, Lausanne, Switzerland. 65-68.

Fortin, Y.; Ilieva, M.; Cloutier, A.; Laforest, P. 1994. Potential use of a semi-ring extensometer for continuous wood surface strain measurement during kiln drying. 4th IUFRO International Wood Drying Conference (A.N. Haslett and F. Laytner), Rotorua, New Zealand. 329-336.

Guitard, D. 1987. Mécanique du matériau bois et composites. Cepadues Editions, Toulouse, France.

Guitard, D.; El Amri, F. 1987. Modèles prévisionnels de comportement élastique tridimensionnel pour les bois feuillus et les bois résineux. Annales des sciences forestières 44(3):335-348.

Hearmon, R. F. S. 1948. The Elasticity of Wood and Plywood. Forest Products Research. Special Report. No. 7, Departement of Scientific and Industrial Research, London, U.K.

Kollmann, F.; Côté, W.A. 1968. Principles of Wood Science and Technology. Volume I: Solid wood. Springer Verlag, New York.

Laghdir, A. 2000. Modélisation de la fissuration en bout de grumes liée aux contraintes de croissance - Application aux Eucalyptus. Ph.D. Thesis, Montpellier University II, France.

Moutee, M.; Fortin, Y.; Fafard, M. 2007. A global rheological model of wood cantilever as applied to wood drying. Wood Sci. Technol. 41(3): 209-234.

Moutee, M.; Fafard, M.; Fortin, Y.; Lahgdir, A. 2005. Modeling the creep behaviour of wood cantilever loaded at free end during drying. Wood Fiber Sci. 37(3): 521-534.

Sliker, A. 1991. Measuring shear moduli in wood with small tension and compression samples. Wood Fiber Sci. 23(1): 58-68.

Sliker, A.; Yu, Y.; Weigel, T.; Zhang, W. 1994. Orthotropic elastic constants for eastern hardwood species. Wood Fiber Sci. 26(1): 107-121.

Yang, J.L; Fortin, Y. 2001. Evaluating strength properties of Pinus Radiata from ultrasonic measurement on increment cores. Holzforschung 55: 606-610. 